\title{
On the role of word frequency in the detection of component letters
}

\author{
NEAL F. JOHNSON, PHILIP A. ALLEN, and TONI L. STRAND \\ The Ohio State University, Columbus, Ohio
}

\begin{abstract}
The experiments reported in this study were conducted to explore the issue of race models versus holistic models of word processing. In both types of model, it is assumed that an available wordlevel encoding for a display will conceal letter information, and thereby inhibit component-letter detection. However, whereas in holistic models it is assumed that encoding always should occur at the word or pattern level first, in the race models it is assumed that encoding occurs at all levels (e.g., feature, letter, and word) simultaneously, with the final level of encoding being at whatever level has been completed first. If the rate of word-level encoding is facilitated by increasing word frequency, the holistic models predict a generally declining latency for letter detection, because the initial step in letter detection (i.e., word-level encoding) will be occurring more rapidly. The race models, on the other hand, predict that with increasing word frequency there will be an increasing chance that the word-level encoding will win the encoding race, resulting in an increase in the latency for letter detection (i.e., the word code will conceal the letter codes). Two experiments are reported, and the obtained pattern of latency data appears to be most consistent with the race models.
\end{abstract}

Perceivers tend to process small visual displays, such as words, holistically. That is, subjects who are asked to respond to a small visual display in some way seem able to react to the display as a whole more rapidly than they can respond to a component of the display. For example, if subjects are given a predesignated target to detect, and if the upcoming display is a word, they will be able to make the detection and respond more quickly if the predesignated target also has been a word, rather than a component letter.

This effect occurs when the target letter is always the first letter of the word, and no search or scan is needed (Johnson, 1975; Johnson \& Marmurek, 1978), as well as when predesignated target words and display words either match perfectly or always mismatch by only a single letter (i.e., if the target were NEST, foil displays might be BEST or NEXT) (Johnson, Turner-Lyga, \& Pettegrew, 1986; Sloboda, 1976, 1977). In addition, in the latter case, even though on letter-detection trials the specific differentiating letter is the target, and the visual information the subjects are using in the two tasks is therefore exactly the same, this is precisely the situation in which some of the largest word-level advantages have been obtained.

There are at least three general classes of models that can be used to account for word recognition, the simplest of which comprises the letter-integration models. In these models, it is assumed that word recognition is preceded by a letter-identification stage, with the letter information then being integrated in some manner to form the word (e.g., see Gough, 1972). In general, it is with such

Correspondence may be addressed to Neal F. Johnson, Department of Psychology, The Ohio State University, 404C W. 17th (East Stadium), Columbus, OH 43210. models that the preceding data seem to be most inconsistent, and for that reason letter-integration models have tended to attract little attention in recent years.

The second class of models consists of those in which the encoding process is viewed as occurring at feature, letter, and word levels simultaneously, with the ultimate level of representation being the one whose level of encoding is completed first. These are the race models, of which the unitization model of Healy and Drewnowski (Drewnowski \& Healy, 1977; Healy \& Drewnowski, 1983) is a good illustration (but see also Chambers \& Forster, 1975). If it is assumed that the word-level representation generally wins the race, then these race models can account for the above data quite well.

The third class of models, which can be termed holis$t i c$, share in general the characteristic assumption that the cognitive encoding of words always occurs at the word level first, and that component-level encoding occurs only after word-level encoding is complete. It is further assumed in holistic models that component-level encoding occurs only when a particular task demands that level of information. Although the pattern-unit model described by Johnson $(1975,1977,1981)$ and the model provided by Johnston and McClelland (1980; Johnston, 1981) are really very different, they do seem to share this particular attribute, and given that this is the case, it is clear that they too account for the foregoing data with little trouble.

The present experiments were designed in an attempt to compare the race models with the holistic models. In terms of a class distinction, the issue is whether component-level encoding is delayed, or whether it begins at the time of input, and within that constraint, whether component-level encoding is automatic or optional. Since the race models, as stated above, involve 
the assumption that encoding begins at all levels at the same time, they would seem to imply that the encoding process occurs at all levels automatically. The holistic models, on the other hand, involve the assumption that encoding begins at the word or pattern level only, that any letter or component-level encoding is delayed until word-level encoding is complete, and that such component level encoding, occurring only if the task demands that type of information, is therefore optional.

In terms of this distinction, there are two experimental outcomes that seem particularly to support the race models. If encoding occurs at all levels simultaneously, and if there is a tendency for word-level representations or codes to conceal their component information (Drewnowski \& Healy, 1977; Healy \& Drewnowski, 1983), then anything that would enhance the rate at which wordlevel encoding occurs should also increase the likelihood that the letter information would be concealed by the word-level code. Pertinent data here are demonstrations that in proofreading tasks the chance of missing a target letter increases with both the reading ability of the subjects (Drewnowski, 1978, 1981) and the cultural frequency of the word that contains the target (Drewnowski \& Healy, 1977; Healy \& Drewnowski, 1983).

Holistic models also lead one to expect that such factors would facilitate the rate at which a word-level encoding is achieved. However, according to these models, word-level encoding should always be successful, regardless of the rate at which it occurs, because encoding at that level is assumed to occur prior to any attempt at component-level encoding. With regard to the availability of the component letters, the fact that there should always be a word-level encoding would mean there should always be a tendency for the letter information to be concealed. Therefore, the relationship between detection errors and the time it would take to obtain the word-level representation ought to be an irrelevant issue.

The core assumption within holistic models is that the encoding which results in the type of cognitive representation needed to make a decision in tasks such as these always occurs first at the pattern or word level. Furthermore, it is assumed that attempts at such holistic encoding always occur, even when the display cannot be represented holistically (e.g., an unfamiliar consonant array), and the knowledge that such a display cannot be unitized in this way is assumed to be obtained through the fact that attempts to unitize it have failed. That is, subjects make some fixed number of unsuccessful attempts at holistic encoding of such displays before giving up the attempt, and it is assumed that they then parse the display into components at some lower level (Johnson, 1977, 1981).

With regard to the current issue, holistic and race models seem to differ in their predictions regarding what will happen if subjects are to react to a component letter of a consonant array, as compared with the same letter presented in isolation. Holistic models suggest that sub jects will initially treat the patterns holistically, and that these attempts will succeed if displays consist of single letters; but if a display is a consonant array (e.g., SBJFQ), the initial attempts will fail, and only then will the display be parsed such that component-level encoding can begin. In addition, this should be true even if the display is redundant, consisting of multiple instances of the same consonant (e.g., BBBBB). That is, as complete patterns, even such redundant displays do not conform to any single prelearned encoding. In general, then, holistic models predict that the presence of other letters will lead to attempts at holistic encoding (albeit unsuccessful ones), but that these attempts should always tend to conceal component letters in the sense of delaying their detection.

With regard to race models, if component letters are concealed to the extent that word- or pattern-level encoding wins the race over letter-level encoding, then consonant arrays should not conceal their component letters. That is, for such displays, no pattern- or word-level encoding can win the race.

The data from the type of task just described (Johnson, 1986; Johnson \& Blum, 1988) seem most consistent with the assumptions underlying holistic models, in that the marked latency advantages obtained for single-letter displays over multiletter displays have occurred even when the multiletter displays were redundant. Furthermore, the disadvantage for the redundant items has been obtained regardless of whether the target letter could only be the first letter of the display, requiring subjects to confine their search to the initial position, or whether the target letter could occur anywhere within the multiletter arrays. In the latter case, for the YES or match items, whatever component letter from the redundant array was encoded first would yield a match with the predesignated target.

The letter-detection advantage for single-letter displays over redundant multiletter displays could be explained within the context of race models by the suggestion that it is just an artifact of an inhibition effect for the redundant arrays, stemming from some type of precognitive perceptual disruption (e.g., lateral masking). That is, the closely adjacent letter(s) in the redundant arrays interfere with the perceptual processing of the item in the target position, and this interference effect, rather than any attempt at pattern-level encoding, slows the response to a component letter.

Recent evidence, however, suggests that the advantage of single-letter displays over multiletter redundant displays may not be a precognitive perceptual effect (Johnson \& Blum, 1988). Specifically, if subjects are given a predisplay fixation field that contains a specific point on which subjects can narrowly prefocus their attention, and if this point conforms exactly to the place in the upcoming multiletter array that they are to examine in order to determine whether the letter matches the predesignated target, then the entire single-letter advantage disappears (cf. Krueger \& Shapiro, 1980).

Given that the effect seems to be based completely on the manner in which subjects deploy their attention, it is clear that some type of attention-driven cognitive process- 
ing is implicated in the effect, but it is less clear how such an attentional effect could arise from precognitive perceptual processing. The data suggest that the effect is not the product of some type of perceptual lateral masking effect.

Because the data from these experiments with redundant consonant arrays, as well as the data reported by Drewnowski and Healy (1977) and Healy and Drewnowski (1983), seem to lead to conflicting conclusions, it is clear that the issue of race as opposed to holistic models is far from being resolved. The present experiments were designed to examine this question further by combining some of the features of the consonant-detection task with the type of variable manipulated by Healy and Drewnowski in their various experiments.

Specifically, if, as expected from holistic models, wordlevel encoding must precede letter-level encoding when words are displayed, then anything that would increase the speed with which subjects can establish the word-level code should also increase the speed with which they can detect a component letter. On the other hand, according to the race models, anything that would increase the rate of word processing should increase the likelihood that word-level encoding would win the race, and that should tend to conceal or decrease the availability of componentletter information.

In general, then, the holistic models would predict that increasing the rate of word processing, by means of increasing the cultural frequency of the displayed words, should decrease the latency of the subjects' detection response (i.e., there should be a negative correlation between latency and word frequency). On the other hand, the race models would predict a positive correlation between word frequency and latency, and it is this issue that these experiments address.

\section{EXPERIMENT 1}

In both experiments there were two basic conditions. One was a task in which subjects were to determine whether a displayed item began with a predesignated target letter, and the second was a standard lexical decision task, in which subjects were to make a positive response if the displayed item was a word and a negative response if it was a pronounceable nonsense item. The displays contained four, five, or six letters, and they were equally divided between pronounceable nonsense items and lowand high-frequency words. The major concern in both experiments was performance on the letter-detection task as a function of word frequency, and the lexical decision task was used as a monitor to ascertain whether the overall effect of word frequency on lexical access was as assumed (i.e., there should be a positive correlation between speed of access and word frequency). In addition, if letter encoding precedes word encoding for low-frequency words, and if there is any serial processing of the letters, then there could be word-length effects for these items in the lexical decision task (i.e., a length $\times$ frequency interaction).

\section{Method}

The nonsense items in this task were constructed from selected English words in which either one or two letters were replaced such that each item was still judged to be pronounceable by two undergraduate assistants, was not listed in Webster's Seventh New Collegiate Dictionary and did not immediately remind either assistant of any English word. The frequency of the words was based on the Kucera and Francis (1967) norms, and the criterion for the lowfrequency items was that they must fall in the frequency range from 20 to 80 , while the range for the high-frequency items was from 100 to 250 . Every item began with a consonant.

There were 144 items representing each of the three types of item, and for each type of item the displays were divided equally into lengths of four, five, and six letters (i.e., 48 items representing each of the nine combinations of length and item type). For purposes of presentation, the 432 items were divided into four lists of 108 items each, with each combination of length and item type being represented by 12 items in each of the lists. For each subject, two lists were used for the letter-detection task and two were used for the lexical decision task, and across subjects, each list was used for each task equally often, and task order was counterbalanced.

In the data analysis, only correct responses were included. In addition, latencies above $1,800 \mathrm{msec}$ and below $300 \mathrm{msec}$ also were eliminated from the analysis, but they were not scored as errors and they were not included in the analysis of the error data (i.e., only incorrect responses were counted as errors).

The apparatus was a Northstar Horizon Computer and two Televideo $920 \mathrm{C}$ terminals (white phosphor), with one terminal as the subject station and the other one used by the experimenter to control the flow of the experiment. For each display, there was a display sequence that began with a predisplay fixation field, which contained three rows of $11 \mathrm{Xs}$, centered on the video screen of the subjects' terminal. That field remained in view for approximately $500 \mathrm{msec}$, after which the screen was cleared and the target display appeared with its first letter conforming to the fourth $X$ of the middle row of the predisplay fixation field. Each character in the display occupied a visual angle of approximately $.3^{\circ}$, and the target item remained in view until shortly after the subjects made each response. The subjects responded by pressing the ?/ key for YES and the $\mathrm{Z}$ key for NO, and the response and the latency were automatically recorded.

For the letter-detection task, the subjects were instructed to determine whether the predesignated target letter matched the initial letter of the display, and they were informed that it would never appear in any other position within the display (it did not). A different predesignated target was used for each display, and the experimenter stated the target aloud approximately $1 \mathrm{sec}$ before the onset of the display sequence. The experimenter then said "ready" and triggered the display sequence. For the lexical decision task, the subjects were instructed to determine whether the display was a word, and except for the fact that the experimenter did not state a predesignated target letter for each display, the presentation sequence was the same as that just described for the letterdetection task.

The subjects were 60 introductory psychology students who participated as part of a course option. They were tested individually, and the experimenter sat beside them during the testing.

\section{Results}

Error data. The error data are presented in Tables 1 and 2. For the lexical decision task (Table 1), errors increased with decreasing word frequency (the nonsense items were considered to have the lowest frequency) $\left[F(2,118)=51.07, M S_{\mathrm{e}}=5.39, p<.001\right]$, and that also occurred when only the high- and low-frequency words were considered $\left[F(1,59)=5.10, M S_{\mathrm{e}}=1.77\right.$, $p<.05]$. In addition, there was a reliable decrease in 
Table 1

Percentage of Errors for the Lexical Decision Task in Experiment 1 Item Frequency

\begin{tabular}{lcccc} 
& & & \multicolumn{2}{c}{ Means } \\
\cline { 5 - 5 } Length & High & Low & Words & Nonwords \\
\hline 4 letters & .67 & 1.67 & 1.17 & 3.13 \\
5 letters & .53 & .63 & .58 & 3.20 \\
6 letters & .78 & .63 & .71 & 2.50 \\
Mean & .66 & .98 & .82 & 2.94 \\
\hline
\end{tabular}

Table 2

Percentage of Errors for the Letter-Detection Task in Experiment 1

\begin{tabular}{|c|c|c|c|c|c|}
\hline \multirow{3}{*}{$\begin{array}{c}\text { Response } \\
\text { Type }\end{array}$} & \multirow[b]{3}{*}{ Length } & \multicolumn{4}{|c|}{ Item Frequency } \\
\hline & & \multirow[b]{2}{*}{ High } & \multirow[b]{2}{*}{ Low } & \multicolumn{2}{|c|}{ Means } \\
\hline & & & & Words & Nonwords \\
\hline YES & 4 letters & 1.05 & 1.43 & 1.24 & 1.30 \\
\hline YES & 5 letters & .80 & 1.25 & 1.03 & 1.47 \\
\hline YES & 6 letters & .92 & 1.05 & .99 & 1.35 \\
\hline Mean YES & & .92 & 1.24 & 1.08 & 1.37 \\
\hline No & 4 letters & .78 & .93 & .86 & 1.23 \\
\hline NO & 5 letters & 1.30 & .92 & 1.11 & .93 \\
\hline NO & 6 letters & 1.00 & 1.13 & 1.07 & 1.25 \\
\hline Mean NO & & 1.03 & .99 & 1.01 & 1.14 \\
\hline Mean & 4 letters & .92 & 1.18 & 1.05 & 1.27 \\
\hline Mean & 5 letters & 1.05 & 1.08 & 1.07 & 1.20 \\
\hline Mean & 6 letters & .96 & 1.09 & 1.03 & 1.30 \\
\hline Grand Mean & & .98 & 1.12 & 1.05 & 1.26 \\
\hline
\end{tabular}

errors as item length increased $\left[F(2,118)=6.00, M S_{\mathrm{e}}\right.$ $=2.12, p<.05]$, and the reliable interaction between length and frequency $\left[F(4,236)=3.81, M S_{\mathrm{e}}=2.43\right.$, $p<.01]$ indicated that there was a general decrease in the effect of frequency as length increased.

The only reliable effect for the error data from the letterdetection task occurred for item frequency $[F(2,118)=$ $\left.3.67, M S_{\mathrm{e}}=1.93, p<.05\right]$. However, when the nonsense items were removed from the analysis, and only the high- and low-frequency words were considered, the difference was not significant $\left[F(1,118)=1.87, M S_{\mathrm{e}}=\right.$ $2.01, p>.05]$.

Latency data. The reaction-time data are presented in Tables 3 and 4. For the lexical decision task (Table 3), the overall effect of length was not significant $[F(2,118)$ $\left.=1.13, M S_{e}=.0026, p>.05\right]$, but there was an effect of frequency (again, the nonsense items were considered the lowest frequency $\left[F(2,118)=135.16, M S_{\mathrm{e}}=.0078\right.$, $p<.01$ ], as well as a length $\times$ frequency interaction $\left[F(4,236)=4.96, M S_{\mathrm{e}}=.0018, p<.01\right]$. For the highand low-frequency words considered alone, the subjects were faster for the high-frequency words than for the low-frequency words $\left[F(1,118)=18.44, M S_{\mathrm{e}}=.0015\right.$, $p<.01]$, and there was a significant effect of length $\left[F(2,118)=7.68, M S_{\mathrm{e}}=.0018, p<.01\right]$, but there was no interaction $\left[F<1.00, M S_{\mathrm{e}}=.0021\right]$.

Regarding the effect of length, the relationship between length and latency was not monotonic, with subjects be- ing faster on the five-letter words than on the four-letter words, and slowest on the six-letter words. In addition, the difference between the four-letter and six-letter words fell short of significance $\left[F(1,59)=3.95, M S_{\mathrm{e}}=.0029\right.$, $p>.05]$. Furthermore, although this pattern was characteristic of both the high-frequency and low-frequency words, the pattern was quite different for the NO responses (i.e., the nonsense items), which gave rise to the interaction in the overall analysis.

The analysis of the letter-detection task (Table 4) indicated no effect of length $\left[F<1.00, M S_{\mathrm{e}}=.0029\right]$, but there was an effect of frequency $[F(2,118)=5.64$, $\left.M S_{\mathrm{e}}=.0050, p<.01\right]$, as well as an effect of response type (YES versus NO) $\left[F(1,59)=132.53, M S_{\mathrm{e}}=.0187\right.$, $p<.01]$. In addition, there was a length $\times$ frequency interaction $\left[F(4,236)=2.49, M S_{\mathrm{e}}=.0040, p<.05\right]$, as well as a frequency $\times$ response type interaction $\left[F(2,118)=3.40, M S_{\mathrm{e}}=.0052, p<.05\right]$, but neither the length $\times$ response type interaction $[F(2,118)=1.42$, $\left.M S_{\mathrm{e}}=.0036, p>.05\right]$ nor the three-way interaction $\left[F<1.00, M S_{\mathrm{e}}=.0032\right]$ was reliable. The interaction between frequency and response type seems to have emerged because the YES-NO difference was smaller for the nonsense items than for the words, but the pattern of data for the length $X$ frequency interaction is much more confused, with the effect of length being unsystematically different for each of the three levels of frequency.

Table 3

Latency Data in Seconds for the Lexical Decision Task in Experiment 1

\begin{tabular}{lcccc} 
& \multicolumn{4}{c}{ Item Frequency } \\
\cline { 2 - 5 } Length & High & Low & Words & Nonwords \\
\hline 4 letters & .604 & .623 & .614 & .746 \\
5 letters & .598 & .613 & .606 & .758 \\
6 letters & .618 & .636 & .627 & .738 \\
Mean & .607 & .624 & .616 & .747 \\
\hline
\end{tabular}

Table 4

Latency Data in Seconds for the Letter-Detection Task in Experiment 1

\begin{tabular}{llcccc}
\hline & & \multicolumn{3}{c}{ Item Frequency } \\
\cline { 5 - 6 } \begin{tabular}{l} 
Response \\
\multicolumn{1}{c}{ Type }
\end{tabular} & Length & High & Low & Words & Nonwords \\
\hline YES & 4 letters & .600 & .584 & .592 & .606 \\
YES & 5 letters & .585 & .580 & .583 & .619 \\
YES & 6 letters & .589 & .595 & .592 & .617 \\
Mean YES & & .591 & .586 & .589 & .614 \\
NO & 4 letters & .704 & .682 & .693 & .692 \\
NO & 5 letters & .698 & .685 & .692 & .710 \\
NO & 6 letters & .693 & .693 & .693 & .681 \\
Mean NO & & .698 & .687 & .693 & .694 \\
Mean & 4 letters & .652 & .633 & .643 & .649 \\
Mean & 5 letters & .641 & .632 & .637 & .665 \\
Mean & 6 letters & .641 & .644 & .643 & .649 \\
Grand Mean & & .645 & .637 & .641 & .654 \\
\hline
\end{tabular}


A separate analysis of the high- and low-frequency words for the letter-detection task indicated that subjects were significantly faster on the low-frequency words than on the high-frequency words $\left[F(1,59)=4.58, M S_{\mathrm{e}}=\right.$ $.0026, p<.05]$ and faster on the YES items than on the NO items $\left[F(1,59)=102.13, M S_{\mathrm{e}}=.0190, p<.01\right]$, but that none of the interactions were significant, with the length $\times$ frequency interaction $\left[F(2,118)=2.01, M S_{\mathrm{e}}\right.$ $=.0038, p>.05]$ being the only one with $F>1.00$. Therefore, whereas increasing word frequency significantly facilitated responding in the lexical decision task, it seemed to have an inhibiting effect in the letter-detection task.

\section{Discussion}

The issue at stake in this experiment was whether increasing word frequency would have a facilitating or an inhibiting effect on letter detection. However, the purpose of including the lexical decision task was for it to function as a monitor for assessing the extent to which the specific variation in word frequency used in this experiment did in fact facilitate lexical access, and the data indicate quite clearly that such was the case. There was a slightly confusing nonmonotonic relationship between length and latency in the lexical decision task, but for the words, that effect did not interact with the effect of word frequency. This result would suggest that the anticipated possible differential length effect for the low-frequency items did not occur, and that the general conclusion regarding the effect of frequency on the nature of lexical access need not be qualified.

With regard to the central issue in the study, the data are equally clear. Although increasing word frequency facilitated lexical access, it inhibited letter detection. This data seems to be most consistent with race models, in that they suggest that component-letter information does tend to be concealed by the very conditions that facilitate lexical access. As noted earlier, holistic views of word processing, such as the pattern-unit model, assume that word-level encoding always should precede componentletter encoding. If this were the case, then anything that would have facilitated lexical access also should have facilitated the detection of component-letter information, but it is quite clear that just the opposite occurred.

\section{EXPERIMENT 2}

One purpose of Experiment 2 was to provide a replication of the basic findings in Experiment 1. Although significant, the absolute magnitude of the inhibiting effect of increasing word frequency on letter detection was really quite small (i.e., $8 \mathrm{msec}$ ), and even though a reliable effect of approximately the same magnitude has been obtained in two unpublished pilot studies, it did seem that a replication would be in order.

The second and major purpose of Experiment 2 was to explore a further implication of the race models. If, as is assumed in those models, letter information is con- cealed when word-level encoding is completed before letter-level encoding, then anything that would increase the speed of word-level encoding, such as increasing word frequency, should also increase the tendency for the letters to be concealed. The results from Experiment 1 are consistent with this expectation.

Yet this prediction is really not quite true. The positive correlation between word frequency and the latency for letter detection should hold only through increases in word frequency up to the point at which it is guaranteed that the word-level encoding will win the race. This point in the word-frequency range will henceforth be referred to as the critical level of word frequency.

If concealment is assumed to be a function of whether word-level encoding wins the race, concealment, and therefore a delay in detection, should be dichotomous. If this is the case, then variation in word frequency below the critical level, and variation above that level, should have no effect on concealment, and only variation in frequency that crosses the critical level should show any effect. Assuming that the critical level of frequency would be approximately the same for most words, then for any word set, such as that used in these experiments, the average degree of concealment should vary from none to a maximum value, over a relatively narrow range of variation in frequency.

Still more important is that if conditions assure that word-level encoding will win the race (e.g., using words whose frequency meets or exceeds the previously described critical level), then anything that will speed up word-level encoding beyond that point also should speed up component-letter detection. That is, under such circumstances, letter information would need to be derived or decoded from the word-level encoding (and the need for such decoding is assumed here to be the cause of the concealment), but the process of decoding the word-level code could begin only after the word-level encoding process was complete. Therefore, the faster the process is completed, the earlier the subject can begin deriving the letter information, which should facilitate subsequent letter detection.

In general, then, a race model would not predict an overall positive correlation between word frequency and the latency for detecting component letters, but rather a curvilinear relationship. The correlation would be positive between low frequencies and moderately high frequencies, in that as frequency increases there should be an increasing likelihood that an item would exceed the critical level of word frequency. However, from moderately high frequencies to very high frequencies there should be a negative correlation between word frequency and latency for letter detection, because that increase in frequency would facilitate the process of deriving or decoding the concealed letters from the word-level code.

\section{Method}

The methods, procedures, and apparatus in Experiment 2 were identical to those used in Experiment 1, with two exceptions. The 
Table 5

Percentage of Errors for the Lexical Decision Task in Experiment 2

\begin{tabular}{lccccc}
\hline & \multicolumn{4}{c}{ Item Frequency } \\
\cline { 2 - 6 } Length & $\begin{array}{c}\text { Very } \\
\text { High }\end{array}$ & $\begin{array}{c}\text { Moderate } \\
\text { High }\end{array}$ & Low & Words & Nonwords \\
\hline 4 letters & .50 & .58 & 1.75 & .94 & 3.77 \\
5 letters & .75 & .08 & .46 & .43 & 2.85 \\
6 letters & .50 & .58 & .71 & .60 & 2.17 \\
Mean & .58 & .42 & .97 & .66 & 2.93 \\
\hline
\end{tabular}

Table 6

Percentage of Errors for the Letter-Detection Task in Experiment 2

\begin{tabular}{|c|c|c|c|c|c|c|}
\hline \multirow{3}{*}{$\begin{array}{c}\text { Response } \\
\text { Type }\end{array}$} & \multirow[b]{3}{*}{ Length } & \multicolumn{5}{|c|}{ Item Frequency } \\
\hline & & \multirow{2}{*}{$\begin{array}{l}\text { Very } \\
\text { High }\end{array}$} & \multirow{2}{*}{$\begin{array}{c}\text { Moderate } \\
\text { High }\end{array}$} & \multirow[b]{2}{*}{ Low } & \multicolumn{2}{|c|}{ Means } \\
\hline & & & & & Words & Nonwords \\
\hline YES & 4 letters & 2.19 & 2.35 & 2.35 & 2.30 & 2.85 \\
\hline YES & 5 letters & 2.58 & .67 & 1.75 & 1.67 & 2.29 \\
\hline YES & 6 letters & 2.06 & .83 & 2.00 & 1.63 & 2.52 \\
\hline Mean YES & & 2.28 & 1.28 & 2.03 & 1.87 & 2.56 \\
\hline NO & 4 letters & 2.37 & 2.38 & 1.92 & 2.22 & 1.27 \\
\hline NO & 5 letters & 1.79 & 1.71 & 1.08 & 1.53 & 1.35 \\
\hline NO & 6 letters & 1.17 & 1.50 & 2.63 & 1.77 & 1.17 \\
\hline Mean NO & & 1.78 & 1.86 & 1.88 & 1.84 & 1.26 \\
\hline Mean & 4 letters & 2.28 & 2.36 & 2.14 & 2.26 & 2.06 \\
\hline Mean & 5 letters & 2.19 & 1.19 & 1.42 & 1.60 & 1.83 \\
\hline Mean & 6 letters & 1.61 & 1.17 & 2.31 & 1.70 & 1.84 \\
\hline Grand Mean & & 2.03 & 1.57 & 1.95 & 1.85 & 1.91 \\
\hline
\end{tabular}

first was that the sample included 48 subjects instead of 60 , though drawn from the same population. The second difference was that half of the high-frequency words in each list were replaced by words of even higher frequency (very high frequency words). The frequency range for the moderately high frequency words was 175 to 260 , which is about the same as for the high-frequency words in Experiment 1, and the range for the very high frequency words was 265 to 1,016 . The low-frequency words and the nonsense items were those used in the first experiment.

\section{Results}

Error data. The error data are presented in Tables 5 and 6. The analysis of the lexical-decision error data (Table 5) indicated a significant effect of frequency (again, the nonsense items are considered to have the lowest frequency) $\left[F(3,141)=49.39, M S_{\mathrm{e}}=3.92, p<.01\right]$ and of length $\left[F(2,94)=11.92, M S_{\mathrm{e}}=2.20, p<.01\right]$, and there was a reliable interaction between frequency and length $\left[F(6,282)=3.92, M S_{\mathrm{e}}=2.76, p<.01\right]$. In general, errors tended to decrease with both increasing frequency and length, and the overall effect of frequency tended to decrease with increasing length. A similar interaction was obtained for the latency data (see below), and the overall correlation between errors and latency is .91. The correlation between errors and latency for just the nine conditions involving words is .30 .

Separate analyses for the lexical decision task to compare just the conditions involving words indicated that there were no differences in errors between the moderately high and the very high frequency words, but both these conditions differed from the low-frequency words, and in both comparisons, the pattern of differences was the same. An analysis of the difference between the low frequency and the very high frequency words indicated that there were reliable effects for both frequency $[F(1,47)$ $\left.=5.34, M S_{\mathrm{e}}=2.04, p<.05\right]$ and length $[F(2,94)=$ $\left.4.90, M S_{\mathrm{e}}=1.77, p<.05\right]$, as well as an interaction $\left[F(2,94)=8.74, M S_{\mathrm{e}}=1.70, p<.01\right]$. For both analyses, the interaction emerged primarily because of the relatively high error rate on the low-frequency four-letter words.

The analysis of the letter-detection error data (Table 6) indicated no frequency effect $\left[F(3,141)=1.15, M S_{\mathrm{e}}=\right.$ $10.19, p>.05]$, and no effect of response type $[F(1,47)$ $\left.=2.68, M S_{\mathrm{e}}=12.70, p>.05\right]$, but there was a nonmonotonic effect of length $\left[F(2,94)=3.66, M S_{e}=9.51\right.$, $p<.05]$. There also was a reliable interaction between frequency and response type $\left[F(3,141)=3.07, M S_{\mathrm{e}}=\right.$ $14.08, p<.05]$, with the effect of frequency being somewhat greater for the YES items. This interaction was also reliable for the latency data, and the correlation between errors and latency for the two sets of eight means involved in that pair of interactions was -.35 , which dropped to -.13 when only words were considered. In addition, the overall correlation between errors and latency for the 18 conditions that involved only words (three levels of frequency and length and two levels of response type) was -.06 .

Latency data. The latency data are presented in Tables 7 and 8 . The overall analysis for the lexical decision data (Table 7) indicated a reliable effect of frequency $[F(3,141)$ $\left.=238.45, M S_{\mathrm{e}}=.0020, p<.01\right]$ and a reliable fre-

Table 7

Latency Data in Seconds for the Lexical Decision Task in Experiment 2

\begin{tabular}{lccccc}
\hline & \multicolumn{3}{c}{ Item Frequency } \\
\cline { 2 - 6 } Length & $\begin{array}{c}\text { Very } \\
\text { High }\end{array}$ & $\begin{array}{c}\text { Moderate } \\
\text { High }\end{array}$ & Low & Words & Nonwords \\
\hline 4 letters & .584 & .580 & .599 & .588 & .706 \\
5 letters & .576 & .591 & .595 & .587 & .703 \\
6 letters & .574 & .583 & .609 & .589 & .692 \\
Mean & .578 & .584 & .601 & .588 & .700 \\
\hline
\end{tabular}

Table 8

Latency Data in Seconds for the Letter-Detection Task in Experiment 2

\begin{tabular}{|c|c|c|c|c|c|c|}
\hline \multirow{3}{*}{$\begin{array}{c}\text { Response } \\
\text { Type }\end{array}$} & \multirow[b]{3}{*}{ Length } & \multicolumn{5}{|c|}{ Item Frequency } \\
\hline & & \multirow{2}{*}{$\begin{array}{l}\text { Very } \\
\text { High }\end{array}$} & \multirow{2}{*}{$\begin{array}{c}\text { Moderate } \\
\text { High }\end{array}$} & \multirow[b]{2}{*}{ Low } & \multicolumn{2}{|c|}{ Means } \\
\hline & & & & & Words & Nonwords \\
\hline YES & 4 letters & .547 & .566 & .559 & .557 & .580 \\
\hline YES & 5 letters & .552 & .566 & .560 & .559 & .588 \\
\hline YES & 6 letters & .557 & .567 & .561 & .562 & .576 \\
\hline Mean YES & & .552 & .567 & .560 & .560 & .582 \\
\hline NO & 4 letters & .639 & .658 & .645 & .647 & .643 \\
\hline NO & 5 letters & .638 & 651 & .641 & .643 & .646 \\
\hline NO & 6 letters & .644 & .658 & .647 & .650 & .642 \\
\hline Mean NO & & .640 & 656 & .644 & .647 & .643 \\
\hline Mean & 4 letters & .593 & .612 & .602 & .602 & .612 \\
\hline Mean & 5 letters & .595 & .609 & .601 & .602 & .617 \\
\hline Mean & 6 letters & .601 & .612 & .604 & .606 & .609 \\
\hline Grand Mean & & .596 & .611 & .602 & .603 & .613 \\
\hline
\end{tabular}


quency $\times$ length interaction $\left[F(6,282)=2.65, M S_{\mathrm{e}}=\right.$ $.0010, p<.05$ ], but the effect of length was not significant $\left[F<1.00, M S_{\mathrm{e}}=.0015\right]$. The interaction seems to have emerged because the effect of length was slightly different for each of the frequency conditions, but the variation does not seem to be systematic in any way. As in Experiment 1, then, the anticipated possible length effect for low-frequency items, which would disappear with increasing frequency, did not materialize.

In terms of the relevant specific comparisons, the latency was longer for the moderately high than the very high frequency items $\left[F(1,47)=4.16, M S_{\mathrm{e}}=.0007, p<\right.$ $.05]$, and it was longer for the low-frequency than the moderately high frequency items $\left[F(1,47)=27.43, M S_{\mathrm{e}}\right.$ $=.0007, p<.01]$. As expected, then, the speed of lexical access seemed to increase with increasing word frequency, although the magnitude of that effect does appear to decrease with increasing word frequency. That is, large frequency differences in the high-frequency range tended to yield smaller latency differences than did smaller frequency differences in the lower frequency range.

The latency data for the letter-detection task are presented in Table 8. An analysis indicated a significant effect of frequency $\left[F(3,141)=8.90, M S_{\mathrm{e}}=.0020, p<\right.$ $.01]$ and response type $\left[F(1,47)=385.01, M S_{\mathrm{e}}=.0049\right.$, $p<.01]$, but the effect of length was not reliable $\left[F<1.00, M S_{\mathrm{e}}=.0018\right]$. The only interaction that yielded $F>1.00$ occurred between frequency and response type $\left[F(3,141)=3.34, M S_{\mathrm{e}}=.0036, p<.05\right]$, but again, the difference in variation was not particularly systematic, with the only point that stands out being the fact that subjects were quite slow when making a positive response to a nonsense item. This may have resulted from the fact that the positive response to nonsense items in the letter-detection task was inconsistent with the negative response subjects made to them in the lexical decision task.

In terms of specific comparisons, the fact that subjects were $9 \mathrm{msec}$ slower on the moderately high frequency items than on the low-frequency items $[F(1,47)=5.23$, $\left.M S_{\mathrm{e}}=.0022, p<.05\right]$ replicates the inhibiting effect of the same range of increasing word frequency that was obtained in Experiment 1, as well as the effects that were obtained in the pilot studies. However, the critical issue was the effect of word frequency on detection latency in the frequency range from moderately high to very high frequency, and, as anticipated, within that range there was a 15-msec drop in latency as frequency increased $[F(1,47)$ $\left.=14.35, M S_{\mathrm{e}}=.0023, p<.01\right]$. The difference between the low-frequency and the very high frequency items was not significant $\left[F(1,47)=3.23, M S_{\mathrm{e}}=.0017\right.$, $p>$.05].

\section{Discussion}

Overall, the results of Experiment 2 seem quite consistent with the group of views of word processing that may be described as race models. First, the lexical decision task was again used to monitor whether word frequency had the expected effect on word-level encoding, and the declining latency with increasing word frequency indicated that this indeed was the case. In addition, once again there seemed to be a nonsystematic relationship between frequency and length for the lexical decision task.

Given the data pattern for the lexical decision task as a background, the curvilinear relationship between word frequency and letter-detection latency is quite striking. Latency for letter detection was quite low for the low and the very high frequency words, whereas subjects responded rather slowly if the word to be searched came from the middle range of word frequency. This data pattern for letter detection seems consistent with the idea that once word encoding is fast enough to beat the rate of letter processing, there should be a reduced availability of letter information, but under this circumstance, there should be a correlation between word availability and letter availability.

\section{GENERAL DISCUSSION}

Overall, the apparent immediate availability of letter information from low-frequency words does seem to be somewhat more consistent with race models than it does with models in which it is assumed that all word processing is holistic. However, this being the case, the conditions under which concealment is expected to occur, and the nature of the interaction between letter and word codes when concealment does occur, take on somewhat greater importance within the model.

With regard to the issue of when concealment occurs, race models predict concealment whenever word-level encoding is faster than letter-level encoding. Similarly, with regard to whether concealment is dichotomous, for any given display occasion, this seems to be a necessary implication of the race models. That is, on any particular occasion, either letter-level encoding wins the race (which would not yield concealment) or word-level encoding wins (which would yield concealment), and the model does not provide for both of them to win to some varying degree.

Given these terms, then, the critical rate of word processing can be defined as the rate that just exceeds the rate of letter-level processing for a particular item on a particular occasion. Rates greater than this value would allow word-level encoding to win the race, with letter concealment then being the result, and rates below this value would allow letter-level processing to win the race.

Clearly, a number of practical considerations dictate that in any real data set there will be some evidence of variability in concealment, even though concealment should occur dichotomously on the occasion of any given display. For example, there should be differences among subjects in the rates at which they encode letters and words, as well as differences among various words and letters in the rates at which they can be encoded by subjects. Furthermore, it is likely that subjects might vary slightly from moment to moment in the rate at which they might encode any given letter or word, depending on a large variety of different context effects and viewing conditions. In addition, although some variations of context and view- 
ing condition might have comparable effects on word and letter processing, it is likely that some, if not most, of such variations would have independent effects on word and letter processing, and this would result in variability in the difference in the encoding rates for letters and words.

Finally, it is likely that any given independent variable (e.g., word frequency) would be related to word processing only indirectly, and therefore the scale values of such a variable can be taken only as a rough estimate or index of processing rate, and not as a direct measure. When this point is combined with the foregoing considerations regarding variability in processing rate, it becomes clear that concealment can be viewed as having only a probabilistic relationship to any particular value of an independent variable, although, depending on the condition, the resulting variability could be quite small. For these reasons, then, any real data set should reflect greater variability in concealment than is implied by the assumed dichotomy of the underlying processing events.

The concept of concealment's being dichotomous yields several specific predictions. First, for any scale or index of the rate of word processing (e.g., word frequency), letter detection should be faster than word identification for values at the low end of the scale, and the rate of word processing should gradually increase across these scale values (i.e., decision latencies should decrease). Second, over a fairly wide range of values at the low end of the scale, it would be expected that the latency for letter detection would not vary, because there would be no variation in concealment. However, in the neighborhood of the scale value that reflects the critical rate for word processing (i.e., what was defined previously as the critical level of the independent variable) there should be a relatively abrupt increase in latency for letter detection (reflecting letter concealment), and the range of scale values over which the latency change occurs (i.e., its abruptness) would be dictated by the factors involved in the foregoing discussion of scale validity and the sources of variability in encoding rate.

In addition, three specific predictions with regard to word-level decisions may be made: First, over the range in which there is an abrupt increase in latency for letter detection, there should be a continuing decrease in latency for word decisions; second, the latency change for the word decisions would be less abrupt in this segment of the scale than for the letter decisions; and third, for word decisions, the latency change in this segment should occur at the same rate as for comparable segments of scale value above and below this range. In general, then, for word-level decisions there should be a gradual and constant decrease in decision latency across the entire scale.

Finally, and again with regard to letter detection, the point in scale value at which the abrupt increase in detection latency reaches its maximum should be the point at which, regardless of subject, word, context, or viewing condition, concealment is always complete (i.e., even the slowest word processing event at this scale value of the index of word processing rate would exceed the critical rate). From this scale value on up to higher values, letter detection would have to pass through preliminary wordlevel encoding, which should mean that any influence of scale value on the latency for word processing would be passed on directly to the latency for letter detection. That is, across this range of scale values, the correlation between the latencies for word-level decisions and letterlevel decisions should be positive and near unity (modulated only by the validity of the scale).

The foregoing predictions can be summarized as follows: (1) Latencies for word-level decisions should gradually decrease as a function of increasing scale values of the index of the rate of word processing; (2) latencies for letter detection should remain low and constant over a wide range of values at the low end of the scale, followed by an abrupt increase in latency over a narrow segment of values in the middle range of the scale, with this increase immediately followed by a gradual decrease in latency as scale values of the index of the rate of word processing increase beyond that point; (3) the range of scale values over which the latency for letter detection increases should be a function of the validity of the scale as an index of rate of word processing, as well as variability in both viewing conditions within the task and processing rates across subjects; and finally, (4) for the letter-detection task, the latency decrease beginning in the middle range of the scale should approximate the rate of decrease in latency for word-level decisions across the same scale values.

The fine grain of these predictions clearly exceeds anything examined in the present experiments, but the experiments do provide support for the predictions' broad outline. In particular, latencies in the word processing task (i.e., lexical decision) did decrease monotonically with increases in the index of word processing rate (i.e., word frequency) while there was a curvilinear relationship between word frequency and letter detection, with detection latency reaching a maximum in the middle range of the scale. The latter result is particularly important. Not only is it quite consistent with expectations based on a race model, but more importantly, it is quite inconsistent with views that assume strict holistic processing.

An important remaining issue concerns how these results can be reconciled with the previously described data that have seemed to provide support for a strictly holistic model. Two points seem to suggest themselves here: First, in almost all of the earlier work, an effort was made to ensure that all displayed words would be familiar to all the subjects (college freshmen), which would have resulted in most of the words' being of very high frequency. Given that such was the case, word-level encoding should have been faster than letter-level encoding. In addition, however, most of the experiments involved a detection task for the word-level decisions, and for a detection task subjects are provided with the predesignated target in ad- 
vance and that would have primed the display item. Given such a prime, word-level processing should be fast for all the items, regardless of their cultural frequency, and the data seem to support this expectation (Johnson, 1977). In general, then, the strong evidence obtained in the past for strict holistic encoding may have been a function of the use of high-frequency words and an experimental paradigm in which the availability of encodings for word displays may have been enhanced by unintentional priming.

\section{REFERENCES}

Chambers, S. M., \& Forster, K. I. (1975). Evidence for lexical access in a simultaneous matching task. Memory \& Cognition, 3, 549-559.

DrewnowsKi, A. (1978). Detection errors on the word the: Evidence for the acquisition of reading levels. Memory \& Cognition, 6, 403-409.

DREWNOWSKI, A. (1981). Missing -ing in reading: Developmental changes in reading units. Journal of Experimental Child Psychology, 31, 154-168.

Drewnowska, A., \& HeALY, A. F. (1977). Detection errors on the and and: Evidence for reading units larger than the word. Memory \& Cognition, 5, 636-647.

Gough, P. B. (1972). One second of reading. In J. Kavanagh \& I. Mattingly (Eds.), Language by ear and by eye (pp. 331-358). Cambridge, MA: MIT Press.

HeALY, A. F., \& DREWnowsKI, A. (1983). Investigating the boundaries of reading units: Letter detection in misspelled words. Journal of Experimental Psychology: Human Perception \& Performance, 9 , 413-426.

JoHNSON, N. F. (1975). On the function of letters in word identification: Some data and a preliminary model. Journal of Verbal Learning \& Verbal Behavior, 14, 17-29.

JoHnson, N. F. (1977). A pattern-unit model of word identification. In D. LaBerge \& S. J. Samuels (Eds.), Basic processes in reading: Perception and comprehension (pp. 91-126). Hillsdale, NJ: Erlbaum.

JoHnson, N. F. (1981). Integration processes in word recognition. In O. Tzeng \& H. Singer (Eds.), Perception of print: Reading research in experimental psychology (pp. 29-64). Hillsdale, NJ: Erlbaum.

Johnson, N. F. (1986). On the detection of letters within redundant arrays. Perception \& Psychophysics, 40, 93-100.

Johnson, N. F., \& BLuM, A. J. (1988). When redundancy hurts letter detection: An attempt to define one condition. Perception \& Psycho physics, 43, 147-155.

JOHNSON, N. F., \& MARMUREK, H. H. C. (1978). Identification of words and letters within words. American Journal of Psychology, 91, $401-415$.

Johnson, N. F., Turner-Lyga, M., \& Pettegrew, B. S. (1986). Partwhole relationships in the processing of small visual patterns. Memory \& Cognition, 14, 5-16.

JoHNSTON, J. C. (1981). Understanding word perception: Clues from studying the word-superiority effect. In $O$. J. L. Tzeng \& H. Singer (Eds.), Perception of print: Reading research in experimental psychology (pp. 65-84). Hillsdale, NJ: Erlbaum.

Johnston, J. C., \& MCClelland, J. L. (1980). Experimental tests of a model of word identification. Journal of Verbal Learning \& Verbal Behavior, 19, 503-524.

KRUEGer, L. E., \& Shapiro, R. G. (1980). Why search for target absence is so slow (and careful!): The more targets there are the more likely you are to miss one. Joumal of Experimental Psychology: Human Perception \& Performance, 6, 662-685.

KuČERA, H., \& FranCIS, W. N. (1967). Computational analysis of present-day American English. Providence, RI: Brown University Press.

SLOBodA, J. A. (1976). Decision times for word and letter search: A wholistic word identification model examined. Journal of Verbal Learning \& Verbal Behavior, 15, 93-101.

SLOBOdA, J. A. (1977). The locus of the word-priority effect in a targetdetection task. Memory \& Cognition, 5, 371-376.

\section{NOTE}

1. Connectionist models also might be considered in these terms, but in the present context that really would be inappropriate (as well as in many other contexts), because connectionism is not so much a theory, or even a class of theories, as it is a format within which a theory can be defined. As is the case with any theoretical format, it is obvious that the metatheoretical commitments of a connectionist format do carry some theoretical baggage, but it is also obvious that the theory itself is defined by the collection of postulates or assumptions it incorporates. In terms of the three types of theory previously defined, any one of them could be instantiated as a connectionist model, given an appropriated set of assumptions, and for this reason the foregoing comments would apply equally to a connectionist formulation.

(Manuscript received September 24, 1987; revision accepted for publication January 3,1989 .) 